\title{
Cure Studies of a Benzoxazine-Based Phenolic Resin by Isothermal Experiment
}

\author{
Jyongsik JANG and Seunghan SHIN \\ Department of Chemical Technology, College of Engineering, Seoul National University, \\ Shinlimdong Kwanakgu, Seoul 151-741, Korea
}

(Received December 5, 1994)

\begin{abstract}
Isothermal cure kinetics of newly synthesized benzoxazine-based phenolic resin were studied by differential scanning calorimetry. The cure reaction of benzoxazine-based pheolic resin follows an autocatalytic mechanism. The conversion at the maximum cure rate was independent of the cure temperature. Assuming that the overall reaction order was second, kinetic parameters of cure reaction for benzoxazine-based phenolic resin were determined from an autocatalytic kinetic model. The modified autocatalytic model has a good agreement with experimental results. In addition, the activation energy and the frequency factor were calculated by the Arrhenius plot.
\end{abstract}

KEY WORDS Isothermal Cure Kinetics / Benzoxazine-Based Phenolic Resin / Autocatalytic / Reaction Order / Activation Energy / Frequency Factor /

The phenolic resin is a classical thermosetting resin that has good thermal property, excellent flame retardancy, and low cost. However, it is brittle and difficult in molecular design, and has a short shelf-life. In addition, phenolic resin uses corrosive acidic catalysts. ${ }^{1-3}$ These shortcomings come from the synthetic method through the condensation reaction of phenolic methylols.

As a way of overcoming these disadvantages, benzoxazine-based phenolic resin (abbreviated to polybenzoxazine) was newly synthesized through the Mannich reaction between phenolic derivatives and the reaction mixture of formaline and aniline. ${ }^{4}$

Polybenzoxazine follows ring-opening mechanism and especially expands during the cure reaction. When it was cured with other thermoset resins, it could reduce the residual stress of the cured material by the alleviation of volume shrinkage. Polybenzoxazine also has excellent mechanical and physical properties. In addition, its processing condition is much simpler than that of classical one because the viscosity of its precursor is lower than that of classical phenolic precursor.

It was well known that the cure kinetics of thermoset material was essential for its applications. Therefore, cure studies for polybenzoxazine are necessary for the determining its practical usages. There are several techniques to monitor the cure process such as d.c. conductivity, infra-red absorption, and differential scanning calorimetry (DSC). ${ }^{5-7}$

DSC has been widely used for the kinetic studies of thermosetting resins. ${ }^{8-12}$ It has been also reported that the kinetic results obtained from isothermal method would be most consistent and reliable. ${ }^{13}$ Therefore, the isothermal technique of DSC was employed in this study to investigate the cure kinetics of polybenzoxazine.

The ultimate goals of this study are not only to elucidate the cure kinetics but also to estimate the kinetic parameters by means of isothermal differential scanning calorimetry 
technique.

\section{EXPERIMENTAL}

\section{Material}

Polybenzoxazine prepolymer was synthesized as follows. Formaline was reacted with aniline in ice bath. After $5 \mathrm{~min}$, the reaction mixture was added to bisphenol-A dioxane solution and then, refluxed for $6 \mathrm{~h}$. Reaction product was purified by treatment of alkali and acidic solution. The final product (A in Figure 1) was white fine powder.

\section{Methods}

Samples were analyzed by a Fourier transform infrared spectrophotometer (Bomem MB-100) equipped with a $1 \mathrm{~mm}$ deuterated triglycine sulfate (DTGS) detector. The spectral range was $4000-600 \mathrm{~cm}^{-1}$. For all spectra, 64 scans were coadded at a resolution of 4 $\mathrm{cm}^{-1}$.

${ }^{1} \mathrm{H}$ NMR measurement was made on VARIAN VXR 200S Fourier Transform nuclear magnetic spectrometer operating at $200 \mathrm{MHz}$. The sample was dissolved in chloroform- $d\left(\mathrm{CDCl}_{3}\right)$ contained TMS as a internal standard.

The calorimetric measurement was conducted using a Perkin Elmer 7 DSC with microprocess controller. The temperature and power calibration of the DSC were optimized for the temperature of $20-300^{\circ} \mathrm{C}$ by using high purity indium as the DSC standard calibration. The heat of conversion was monitored in $\mathrm{N}_{2}$ atmosphere.

The isothermal method was used in this study. Sample cell was introduced to sample holder at load temperature. The load temperature was fixed at $150^{\circ} \mathrm{C}$. The sample was heated to experimental temperature by $100^{\circ} \mathrm{C} \mathrm{min}^{-1}$ heating rate. Thermal equilibrium was achieved<smiles>CC(C)(c1ccc(O)cc1)c1ccc(O)cc1</smiles>
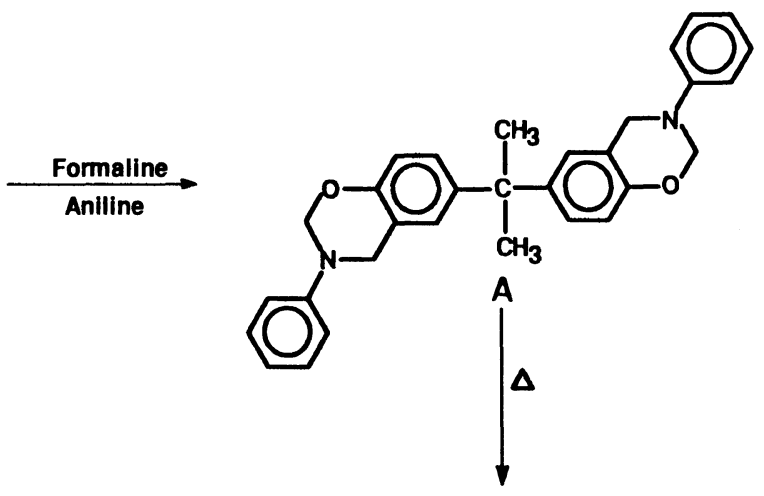<smiles>CCc1cc(C(C)(C)CC)cc(CN(CC)c2ccccc2)c1O</smiles><smiles>CC(C)(C)CN(Cc1cc(C(C)(C)C)cc(CN(Cc2cc(C(C)(C)C)cc(C(C)(C)C)c2O)c2ccccc2)c1O)c1ccccc1</smiles>
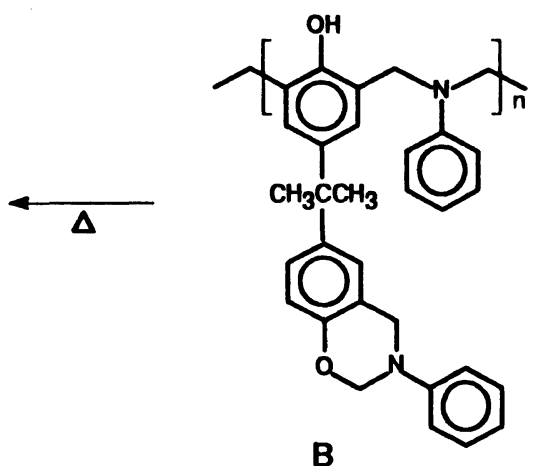

Figure 1. The schematic cure reaction of polybenzoxazine. 
within a minute after temperature had risen.

The rate of reaction, $\mathrm{d} \alpha / \mathrm{d} t$, was determined directly from DSC thermograms

$$
\frac{\mathrm{d} \alpha}{\mathrm{d} t}=\frac{(\mathrm{d} H / \mathrm{d} t)}{H_{\text {com }}}
$$

where $\alpha$ is the extent of cure, $H_{\text {com }}$ is the complete heat of cure obtained from $10^{\circ} \mathrm{C}$ $\min ^{-1}$ heating rate. In order to get the extent of conversion, the DSC curves were integrated and the partial areas as a function of time were normalized with respect to $H_{\text {com }}$ and sample weight.

\section{RESULTS AND DISCUSSION}

The schematic cure reaction of polybenzoxazine was illustrated in Figure 1. The cure reaction followed a ring opening mechanism. As the polybenzoxazine was cured, $-\mathrm{CH}_{2}-\mathrm{O}$ group in benzoxazine unit disappeared and hydroxy group appeared. The FT-IR spectra of pristine and cured polybenzoxazine were shown in Figure 2. From these spectra, it could be known that the band at $1048 \mathrm{~cm}^{-1}$ due to the $-\mathrm{CH}_{2}-\mathrm{O}-$ group disappeared completely after curing reaction. It was also observed that hydroxy stretching band appeared at 3600 $3200 \mathrm{~cm}^{-1}$ as a result of curing reaction.

${ }^{1} \mathrm{H}$ NMR spectrum showing the structure of polybenzoxazine was given in Figure 3 with proper assignments. It shows that the $\mathrm{CH}_{3}$ groups in isopropylidene appear not singlet but doublet. Therefore, it could be known that the product which is asymmetric isopropylidene also exists.

Isothermal DSC thermograms of polybenzoxazine with different cure temperatures were shown in Figure 4 . The cure rate of polybenzoxazine passes through a maximum

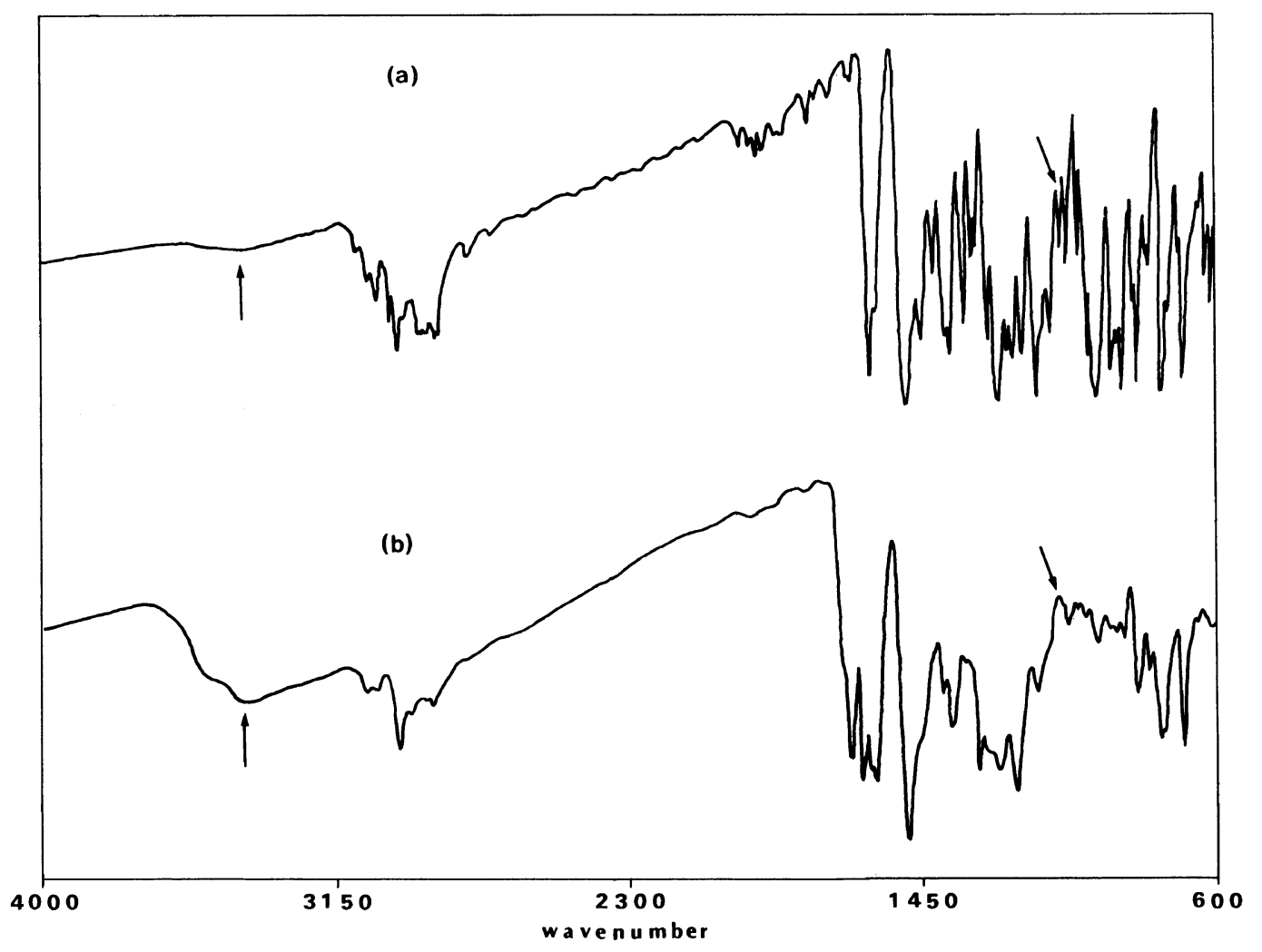

Figure 2. FT-IR spectra of polybenzoxazine: (a) uncured; (b) cured. 


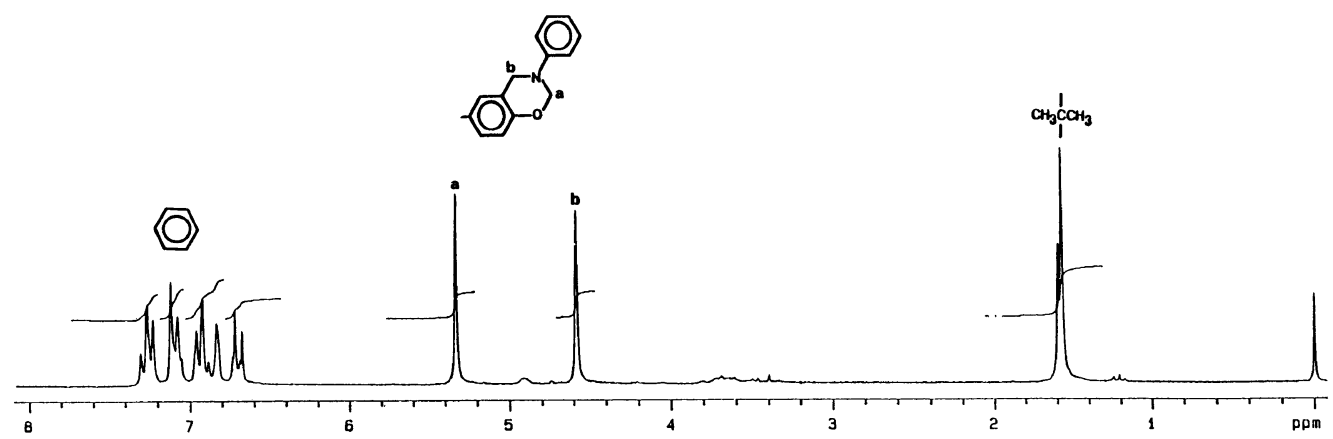

Figure 3. ${ }^{1} \mathrm{H}$ NMR spectrum of polybenzoxazine.

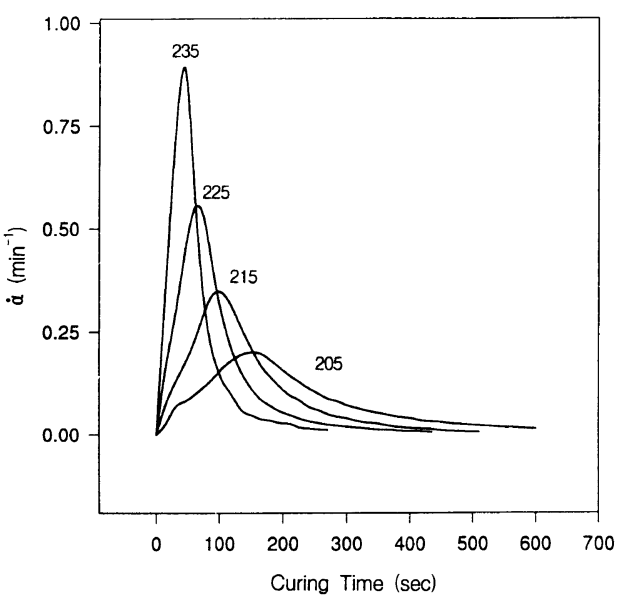

Figure 4. Cure rate as a function of cure time. The numbers in the figure indicate cure temperatures $\left({ }^{\circ} \mathrm{C}\right)$.

point and then decreases as a function of cure time. The cure rate at peak $\left(\dot{\alpha}_{\mathrm{p}}\right)$ increases with increasing the cure temperature. These facts indicate that cure reaction of polybenzoxazine follows autocatalytic reaction.

In general, autocatalytic reaction follows a complicated mechanism. The reaction rate is accelerated in early stage, but the reaction is controlled by diffusion in post-gelation stage. As a result, the reaction rate sharply decreased in post-gelation stage.

The degree of conversion as a function of curing time was illustrated in Figure 5. It shows that the degree of conversion increased with increasing curing temperature at a given time. However, at curing temperature of $235^{\circ} \mathrm{C}$, the

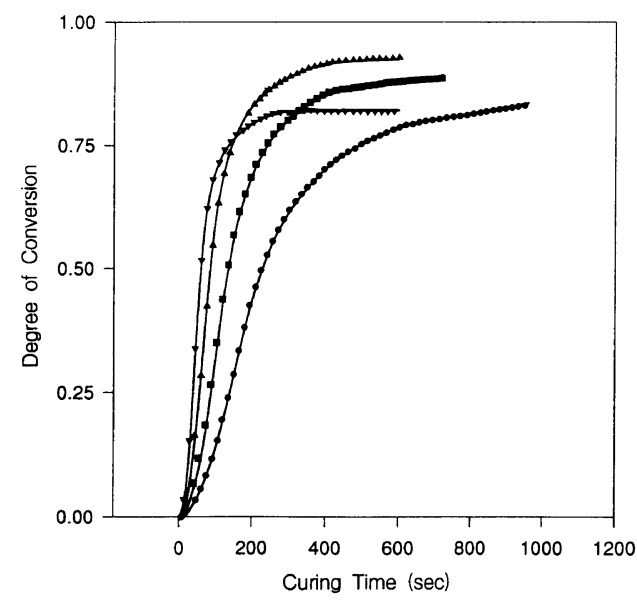

Figure 5. Degree of conversion as a function of curing time: $205^{\circ} \mathrm{C}(\mathbf{O}), 215^{\circ} \mathrm{C}(\boldsymbol{\square}), 225^{\circ} \mathrm{C}(\boldsymbol{\Delta})$, and $235^{\circ} \mathrm{C}(\boldsymbol{\nabla})$.

increase of the degree of conversion was alleviated after $150 \mathrm{~s}$. Its maximum degree of conversion was lower than those of the others.

The conversion at the maximum cure rate $\left(\alpha_{p}\right)$ was independent of the cure temperature as shown in Figure 6. Maximum cure rates existed between 0.30 and 0.34 conversion. This result also indicates that the curing reaction of polybenzoxazine follows autocatalytic mechanism.

Because the initial kinetic constant was zero in this system, the following equation was used to determine the kinetic constant.

$$
\dot{\alpha}=\frac{\mathrm{d} \alpha}{\mathrm{d} t}=k(1-\alpha)^{n} \alpha^{m}
$$




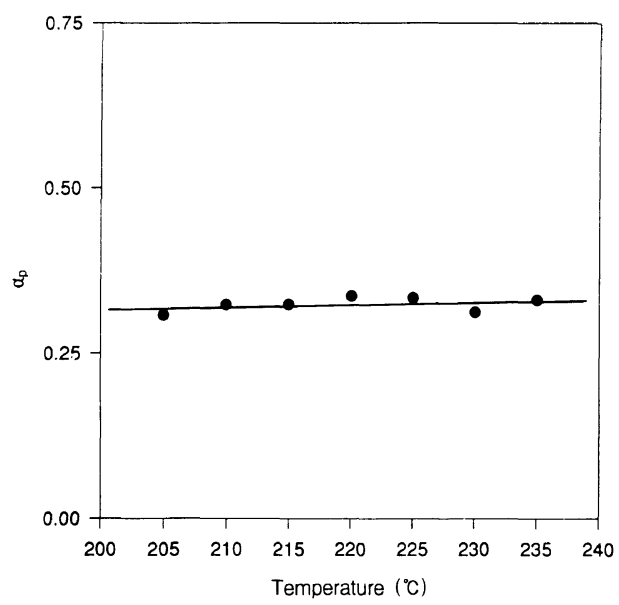

Figure 6. Degree of conversion at peak as a function of cure temperature.

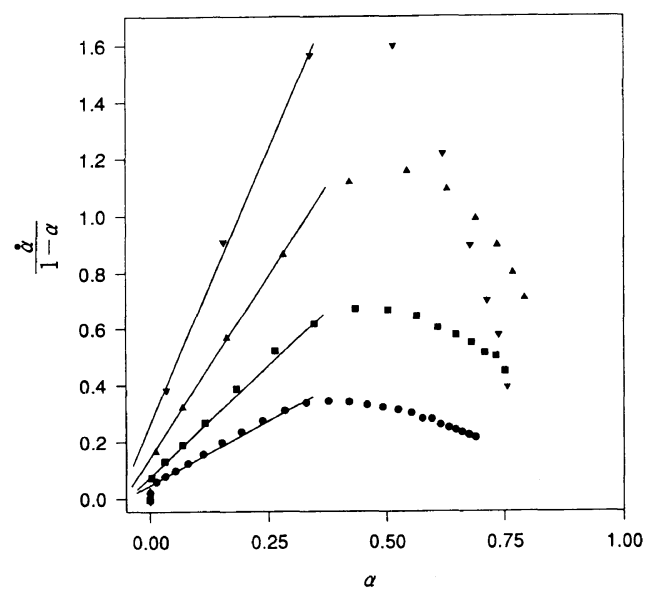

Figure 7. $\dot{\alpha} /(1-\alpha)^{n}$ versus $\alpha^{m}$ in the case of $m=n=1$; $205^{\circ} \mathrm{C}(\bigcirc), 215^{\circ} \mathrm{C}(\boldsymbol{\square}), 225^{\circ} \mathrm{C}(\boldsymbol{\Delta})$, and $235^{\circ} \mathrm{C}(\boldsymbol{\nabla})$.

where $\alpha$ is the degree of conversion, $k$ is the kinetic constant, $m$ and $n$ are kinetic exponents.

It was reported that overall reaction order $(m+n)$ of polybenzoxazine was approximately second. ${ }^{14}$ Figure 7 shows the plots of $\dot{\alpha} /(1-\alpha)^{n}$ versus $\alpha^{m}$, in case of $m=n=1$. The linearities were maintained up to about $35 \%$ conversion.

In order to obtain the accurate reaction order, eq 2 was manipulated as follows.

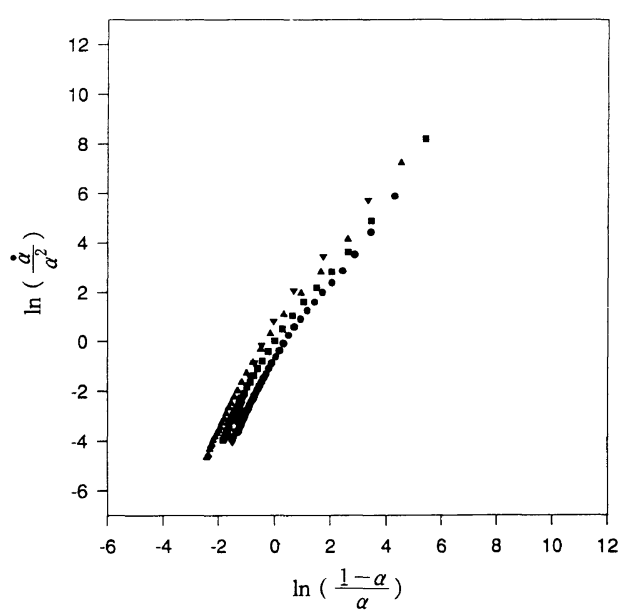

Figure 8. The plot of $\ln \left(\dot{\alpha} / \alpha^{2}\right)$ versus $\ln (1-\alpha) / \alpha: 205^{\circ} \mathrm{C}$ $(\boldsymbol{O}), 215^{\circ} \mathrm{C}(\boldsymbol{\square}), 225^{\circ} \mathrm{C}(\boldsymbol{\Delta})$, and $235^{\circ} \mathrm{C}(\boldsymbol{\nabla})$.

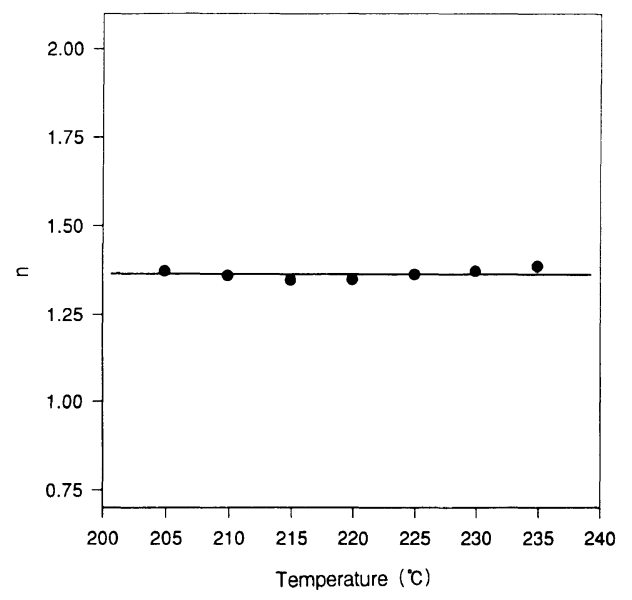

Figure 9. Kinetic parameter $n$ as a function of cure temperature.

$$
\ln \left(\frac{\dot{\alpha}}{\alpha^{2}}\right)=\ln k+n \ln \left(\frac{1-\alpha}{\alpha}\right)
$$

Figure 8 shows the plot of $\ln \left(\dot{\alpha} / \alpha^{2}\right)$ versus $\ln ((1-\alpha) / \alpha)$. The plots with different curing temperature are approximately linear in the middle range. The slope of the plot was reaction order $n$. The values of reaction order $n$ calculated by this method were plotted in Figure 9. The values of $n$ were nearly constant irrespective of curing temperature. 


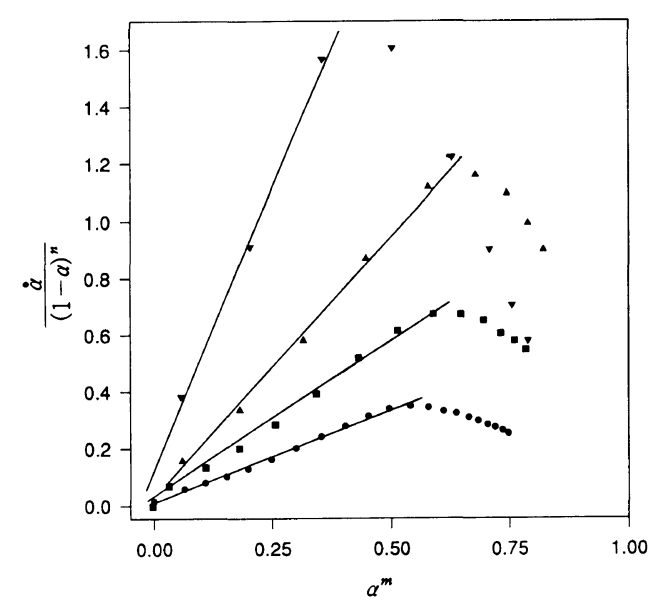

Figure 10. $\dot{\alpha} /(1-\alpha)^{n}$ versus $\alpha^{m}$ by using calculated kinetic parameters: $205^{\circ} \mathrm{C}(\odot), 215^{\circ} \mathrm{C}(\boldsymbol{\square}), 225^{\circ} \mathrm{C}(\boldsymbol{\Delta})$, and $235^{\circ} \mathrm{C}$ (V).

Table I. The kinetic variables of polybenzoxazine

\begin{tabular}{ccc}
\hline Kinetic variables & Value & $\begin{array}{c}\text { Correlation } \\
\text { coefficient }\end{array}$ \\
\hline$E_{\mathrm{a}} / \mathrm{kJ} \mathrm{mol}^{-1}$ & 101.3 & -0.996 \\
\hline$A / \mathrm{s}^{-1}$ & $1.23 \times 10^{-9}$ & \\
\hline
\end{tabular}

The determined reaction order $m$ was 0.63 and $n$ was 1.37 . The plots of $\dot{\alpha} /(1-\alpha)^{n}$ versus $\alpha^{m}$, using these kinetic orders, were shown in Figure 10. Linearities of these plots indicate a good fitting with experimental results and the data obey the model up to approximately $50 \%$ conversion. Compared to the assumption of $m=n=1$, this modified manipulation of the autocatalytic model would be more adequate for polybenzoxazine.
The activation energy $\left(E_{\mathrm{a}}\right)$ and the frequency factor for the apparent kinetic constant $(k)$ for polybenzoxazine were determined by the Arrhenius plot. The Arrhenius plot was plotted by using the kinetic constants obtained from the slopes of plots in Figure 10 and the cure temperatures concerned. The determined values were shown in Table I.

\section{REFERENCES}

1. H. F. Mark, N. M. Bikales, C. G. Overberges, and G. Menges, "Encyclopedia of Polymer Science and Engineering," Vol. 11, John Wiley \& Sons, New York, N.Y., 1988, p 45.

2. T. L. Richardson, "Industrial Plastics," Delmar Publishers Inc., New York, N.Y., 1989, Chapter 8.

3. H. Domininghaus, "Plastics for Engineers," Hanser Publishers Inc., Munich, 1993, Chapter 19.

4. H. Ishida, "The preprints of the 35th IUPAC International Symposium on Macromolecules", Akron, Ohio, U.S.A., July 11-15, 1994, p 542.

5. K. Horie, H. Hiura, M. Sawada, I. Mita, and H. Kambe, J. Polym. Sci., 8, 1357 (1970).

6. R. A. Fava, Polymer, 9, 137 (1968).

7. M. A. Acitelli, R. B. Prime, and E. Sacher, Polymer, 12, 333 (1971).

8. R. B. Prime, Polym. Eng. Sci., 13 (5), 365 (1973).

9. M. E. Ryan and A. Dutta, Polymer, 20, 203 (1979).

10. C. C. Riccardi, H. E. Adabbo, and R. J. Williams, J. Appl. Polym. Sci., 29, 2481 (1984).

11. J. Shim, W. Lee, and J. Jang, Polym. J., 23, 903 (1991).

12. J. Shim, W. Lee, and J. Jang, Polym. J., 23, 911 (1991).

13. R. B. Prime, "Thermal Characterization of Polymeric Materials," Academic Press, Inc., New York, N.Y., 1984, Chapter 5.

14. H. Ishida and Y. Rodriguez, "The preprints of the 35th IUPAC International Symposium on Macromolecules", Akron, Ohio, U.S.A., July 11-15, 1994, p 634. 